\title{
The Characteristics Of Wound In Child Abuse Cases In R. M. Djoelham Binjai General Hospital In 2019-2020
}

\author{
Reza Priatna, Adriansyah Lubis, Rizki Arviandi \\ Forensic and Medicolegal Department \\ Faculty of Medicine North Sumatera University \\ DOI: 10.29322/IJSRP.11.11.2021.p11945 \\ http://dx.doi.org/10.29322/IJSRP.11.11.2021.p11945
}

\begin{abstract}
Child abuse is an act which involved of persecution or mistreatment to children in the form of physical, emotional, and sexual abuse and neglecting childcare. Child abuse was often undetected because children has not been able to express their experience to doctor, regarding to an abuse that they had experienced. The rate of child abuse in North Sumatera, especially in Binjai city was increasing every year, however, there hasn't been any study about the type of abuse, which part of the body abused, and the qualification of the degree of the wound. This is an observational study with descriptive design using a retrospective approach. This study was conducted in R. M. Djoelham Binjai General Hospital and the samples were the result of Visum et Repertum from the victims of child abuse under 18 years old in 2019 to 2020 . The rate of child abuse was dominated by male children in 12-18 years old. In most of the reported cases (61\%), there were more than 1 wound, and there were some cases (57\%) in which the victims had only one wound around head area, most of the cases were caused by blunt trauma (98\%) with bruises and there were almost an equal amount of mild degree (50\%) and moderate degree wound (50\%). This descriptive study showed that in Binjai City from 2019-2020, the characteristic of child abuse was blunt trauma, with multiple wound, mostly in head area and were not lethal.
\end{abstract}

Index Terms- Characteristic of wound, child abuse, Binjai City

\section{INTRODUCTION}

$\mathrm{C}$ hild abuse is not only a social or law issues, but also a community medicine problem. Child abuse issue is not a standalone issue but are affected by several interacting factors. Child abuse also known as child maltreatment is a purposeful act conducted by a parents or friends. Child abuse can be found as a physical, sexual, emotional abuse and neglecting childcare.

There were several factors that contributes to the incidence of child abuse, such as parenting method, content of Television consumed, or games that has a physical or non-physical violence content, permissiveness of surrounding environment, friends, or the culture in either their educational or living environment. Educational and living environment is very vulnerable, with the increasing number of bullies from seniors, friends, etc. Weak physical condition and lower social awareness were mostly the factors that triggered child abuse.

Child abuse was often undetected because children has not been able to express their experience to doctor, regarding to an abuse that they had experienced. Doctor's awareness is crucial because at their respective age, it was very common for a child to have a scar accidentally when they were in their daily activities such as playing. In this regards, clinical forensic aspect is important. Doctor should be able to understand the psychological and physical condition of the children, is the wound were an accidental wound from playing, or is it due to child abuse.

The rate of child abuse in North Sumatera was increasing. From January to July in 2019, there were 526 children experiencing child abuse in North Sumatera. There were 248 cases of physical abuse, 239 cases of sexual abuse, 61 cases of child abandonment and 5 cases of child trafficking. In Binjai city, in North Sumatera, according to the Department of Women Empowerment and Child and Society Protection, from January to November in 2020, there were 29 cases of woman and child abuse. However there has been no study in prior to the type of abuse, the location of the abuse in the victim's body, and the qualification of the wound grade. Based on all of these, the author aims to conduct this study.

\section{METHOD}

This is an observational study with descriptive design using retrospective approach based on the data from Visum et Repertum. The study was conducted from, June 2021 to October 2021 in the Department of Forensic in R. M. Djoelham General Hospital, Binjai city.

The Sample in this study were all the result of forensic examination (total sampling) in the form of Visum et Repertum of a victim of child abuse in Binjai city in 2019-2020 using a criterion of inclusion and exclusion. The samples in this study must fulfil the criteria of inclusion and the criteria of exclusion. The criteria of inclusion in this study were the Visum et Repertum of living victim, male and female child under 18 years old who had experienced a mechanical trauma abuse. The criteria of exclusion were: Visum et Repertum of a traffic accident, and Visum et Repertum of a sexual abuse case.

The data collected from all the Visum et Repertum will be categorized according to each variable and then analyzed using SPSS software. The data will be analyzed with univariate analysis to configure the distribution and the frequency of the variables. The result will be shown in a table and graphic according to each category. 


\section{RESULT AND DISCUSSION}

The total number of Visum et Repertum of child abuse cases in R. M. Djoelham Binjai General Hospital was 61 visum report, however, there were only 44 that fulfilled the criteria of inclusion. There were 17 visum reports that did not fulfill the criteria of inclusion due to several factors such as a visum report with the conclusion of no signs of violence ( 8 visum reports), cases of sexual abuse ( 8 visum reports) and 1 cases of thermal trauma (1 visum report).

The characteristic of the samples in this study was shown based on the distribution of their age and sex, as shown in Table 1.

Table 1. Characteristic of Samples

\begin{tabular}{llll}
\hline CHARACTERISTIC & INFO & $\mathbf{N}$ & $\%$ \\
\hline AGE & $0-5$ & 1 & $2 \%$ \\
& $6-11$ & 10 & $23 \%$ \\
& $12-18$ & 33 & $75 \%$ \\
\hline SEX & Male & 33 & $75 \%$ \\
& Female & 11 & $25 \%$ \\
\hline
\end{tabular}

Based on the distribution by age, it was found that the youngest child was 3 years old and the oldest was 17 years old. The highest incidence of child abuse was reported in the group of children around 12-18 years old, followed by the group with 6-11 years old and the least was in the group of children around 0-5 years old. From these results, it was shown that an increase of age also increases the susceptibility of a child to experience child abuse. Toddlers spends most of their time with their parents in their house, however as the child gets older, the behavior of the child was being affected more by the mass media and the environment in which the child grew including their friends either around their house or their school. The result of this study showed that most of the child abuse cases were an abuse by the child's friends compared to their parents, this result was different to the common findings that showed that most of the child abuse cases was found in a household. This result could be because the children were unable to report their own parents to the law enforcement and to make visum report.

Based on the distribution by sex, it was found that male (75\%) experienced more child abuse compared to female (25\%). This result was similar with prior study conducted by Alit et al, which found that the prevalence of child abuse in male children was $29 \%$ compared to $11 \%$ in female. This result may also be affected by the local culture in which male children was more open about their experience compared to female children. This result was different from the result of prior study conducted by Janise CL et al., in Manado city in 2013, which found that female children have a higher percentage of child abuse cases compared to male.

The characteristics of the wound in child abuse cases were classified into 4 categories, which were the number of wound, the location of wound, type of wound and wound degree, which can be seen in Table 2 .
Table 2. Characteristic of Wound in Child Abuse Cases

\begin{tabular}{|c|c|c|c|}
\hline VARIABLES & & $\mathbf{N}$ & $\%$ \\
\hline \multirow{2}{*}{$\begin{array}{l}\text { NUMBER } \\
\text { WOUND }\end{array}$} & One & 17 & $39 \%$ \\
\hline & More than one & 27 & $61 \%$ \\
\hline \multirow{2}{*}{$\begin{array}{l}\text { LOCATION } \\
\text { WOUND }\end{array}$} & One Location & 25 & $57 \%$ \\
\hline & More than one & 19 & $43 \%$ \\
\hline \multirow[t]{3}{*}{ TYPE OF WOUND } & Sharp & 0 & $0 \%$ \\
\hline & Blunt & 43 & $98 \%$ \\
\hline & Firearms & 1 & $2 \%$ \\
\hline \multirow[t]{3}{*}{ WOUND DEGREE } & Mild & 22 & $50 \%$ \\
\hline & Moderate & 22 & $50 \%$ \\
\hline & Severe & 0 & 0 \\
\hline
\end{tabular}

The result on the characteristic of wound based on the number of wounds showed that most of the children have more than one wound (27 children) compared to those with only one wound (17 children). This showed that child abuse was often experienced repeatedly by the child. This result was similar with the data from the Ministry of Health, in which there was $40 \%$ cases of child abuse in Indonesia in children around 13-15 years old in which they had experienced at least one abuse in a year.

Based on the result of this study it was found that most of the cases had more than one location of abuse. The wound was found in several parts of the body such as head, neck, chest, abdomen, back, butt, upper extremities, and lower extremities.

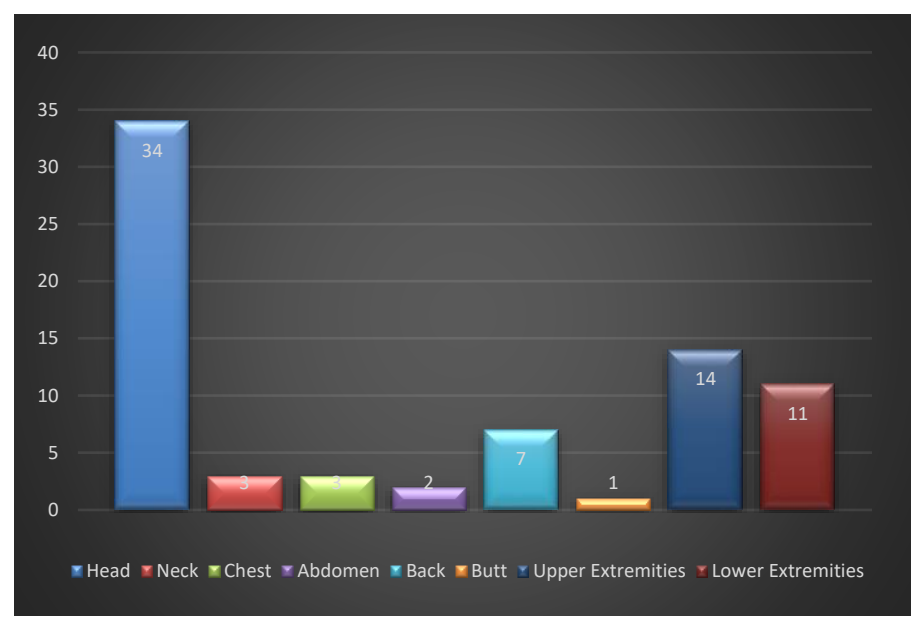

Picture 1. Location of the wound in child abuse cases

This study showed that the highest number of wounds was in head area, which were 34 cases, followed by upper extremities and lower extremities. This result was similar with prior study conducted by Affandi which found that head area was the most common location of the wound in child abuse cases. Head was mostly involved in child abuse because it was easily reach by the perpetrator, also the extremities were often involved, probably because during the abuse, the victims tried to block the attack from the perpetrator.

There were several kinds of mechanical wound trauma, such as sharp wound trauma, blunt wound trauma, and firearms trauma. in this study, blunt trauma was found in most of the child 
abuse reports which were 43 cases, with 1 case of firearms trauma and no cases of sharp wound trauma.

The most type of wound found in this study was bruises which were found in 34 cases, followed by abrasive wound in 27 cases and open wound in 7 cases. The result of this study was similar with prior study conducted by Iswara et al., in Semarang city that found that most of the wound found in child abuse cases were blunt wound trauma compared to other type of trauma.

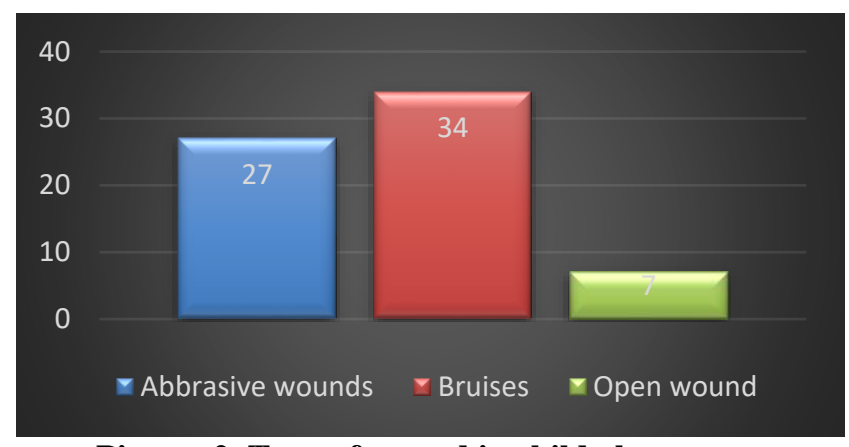

Picture 2. Type of wound in child abuse cases

According to Indonesia Criminal Code, the degree of wound can be classified into 3 classes, which is mild degree, moderate degree, and severe degree. In this study, most of the wound found were mild and moderate degree, there was no cases of severe degree wound in the samples of this study. Mild degree wound was found in 22 cases, equal with the number of moderate degrees wound which is also 22 cases. Most of the wound were not life-threatening. This was similar with prior study that stated that most of the wound were not lethal, but only meant to warn the children.

\section{CONCLUSION AND SUGGESTION}

Based on the result of this study which was conducted in R. M. Djoelham Binjai General Hospital about the characteristic of wound in child abuse in children from 2019-2020, it can be concluded that child abuse was mostly found in children around 12-18 years old, in male children, mostly with more than one wound, mostly in head area with the most type of wound was blunt wound trauma with bruises, the degree of wound in this study was equal between mild degree wound and moderate degree wound (non-lethal).

The sample in this study was obtained using the total sampling method with a total of 44 samples in 2 years of visum record. The number of the samples in this study was minimal. The author suggests that another study which involves a wider and larger number of samples can be performed to give a better picture of child abuse cases.

\section{AUTHORS}

First Author - Reza Priatna, Forensic and Medicolegal Department, Faculty of Medicine North Sumatera University, Email: rjpr11111@gmail.com

Second Author - Adriansyah Lubis, Forensic and Medicolegal Department, Faculty of Medicine North Sumatera University Third Author - Rizki Arviandi, Forensic and Medicolegal Department, Faculty of Medicine North Sumatera University 